\section{Integrity rehab leader responds}

As leader of the programme for Restoring Professionalism and Integrity in Research (RePAIR; see Nature 493, 147; 2013), I wish to correct some popular assumptions about its approach.

The RePAIR programme offers remediation for researchers who have been persistently noncompliant or engaged in wrongdoing. It is not an alternative to preventing non-compliance in the first place. Neither is it suitable for all violators: before referring an investigator, an institution must believe that he or she is talented and capable of reform.

The programme was not designed primarily for researchers guilty of falsification, fabrication or plagiarism. All those referred so far have failed to protect human subjects, to care for animals properly, or to declare and manage conflicts of interest.

Most investigators remain in their field after disciplinary action. RePAIR responds to this fact, partly to avoid compromising the future of co-workers (see J. M. DuBois et al. Clin. Transl. Sci. http://doi.org/kp6; 2013).

Complex compliance demands make researchers more prone to falling foul of the rules, particularly when they are under stress from time constraints and funding pressures. More education in ethics is not the answer: instead, proper strategies are needed for managing stress, solving professional problems and dealing with obstacles to compliance. For this reason, the RePAIR programme was designed not by ethicists but by a team of specialized psychologists. James M. DuBois Saint Louis University, St Louis, Missouri, USA. duboisjm@slu.edu

\section{Funding: some sense in overlapping grants}

I believe it makes sense in these straitened times to submit scientifically overlapping grant applications to multiple agencies, in the hope that one will receive funding (Nature 493, 577, 2013).

It would, of course, be unethical to accept duplicate budgets for the same salary or equipment. But overlapping funding is often used to expand and upgrade laboratory resources, particularly if one grant provides insufficient support to follow up the scientific leads and questions that always pop up along the way.

A simpler, more efficient system could be achieved with more overlap, not less. One solution might be a centralized proposal repository (N. Y. Harel Nature 452, 409, 2008), into which individual researchers could submit one proposal for review by multiple agencies. Several agencies might then share the costs of (and credit for) the same project.

Instead of sleuthing to identify other agencies that received similar proposals, funders could use text-similarity software to find and collaboratively fund the proposals that are most relevant to their missions. A system of overlapping funding would also encourage more transparency. Noam Y. Harel Icahn School of Medicine at Mount Sinai; and James J. Peters Veterans Affairs Medical Center, New York, USA. noam.harel@mssm.edu

\section{Funding: database to counter duplication}

An initiative by the International Cancer Research Partnership (ICRP; chaired by S.B.R.) is helping to address the problem of duplicate funding for similar research (Nature 493, 577; 2013 and Nature 493, 599-601; 2013).

The ICRP represents 56 cancer-research organizations in the United States, Canada, the United Kingdom, France, the Netherlands, Australia and Japan. It curates a publicly accessible database of details of each partner's funding and research (see go.nature.com/ckanbr).

Around one-third of our partners ask grant applicants to interrogate this database for overlapping and complementary research. Other partners use the database as an internal administrative tool to assess potential duplication of effort. The process is straightforward because all awards are structured using an international

classification system known as the Common Scientific Outline.

At the ICRP, we believe that cancer research should be a coordinated and collaborative global enterprise, with maximally efficient use of scarce resources. We therefore invite other cancerresearch organizations to join us in order to meet these objectives. Stephanie Birkey Reffey Susan G. Komen for the Cure, Washington DC, USA.

Lynne Davies ICRP, Cancer

Research UK, London.

lynne.davies@cancer.org.uk

\section{Marine monitoring is hard and costly}

While fisheries scientists are still struggling with uncertainties in stock assessments for single species (Nature 494, 282; 2013), a giant leap towards a whole-ecosystem approach is being embedded into international policies for fisheries management. However, underwater monitoring of a huge and complex range of environmental and biological processes will be difficult and costly.

The unsustainable use of a resource can have knock-on effects within an ecosystem, as well as socioeconomic repercussions. If budget constraints limit the monitoring of whole communities, however, population estimates and predictions could be compromised, possibly masking a species decline and leading to misguided policy decisions. Governments should not be tempted to find inexpensive solutions to fulfil policy requirements and to meet deadlines.

There are tools available to help countries pinpoint problems, direct research efforts, quantify acceptable limits for degradation, calculate the monitoring effort needed to detect a meaningful change, and gather resources for implementing a useful strategy (see B. S. Halpern et al. Nature 488, 615-620; 2012).

Miguel Pessanha Pais Centre for Oceanography, University of Lisbon, Portugal. mppais@fc.ul.pt

\section{Use foreign aid to help African science}

Scientific and technological research could solve many of Africa's local issues, but these problems persist despite generous international support.

The situation is made worse by a severe shortage of well-trained, home-grown scientists, and aggravated by emigration and poor working environments (see, for example, M. H. Hassan Cell 131, 433-436; 2007). Countries in Africa lack adequate equipment, have no running budgets and almost no ethics codes or regulations. These factors also discourage African scientists trained abroad from returning home and applying their valuable skills.

Solutions derived from the developed world are unlikely to work, because Africa's reality is centuries behind and there is no infrastructure for implementing them. It is a matter of priority to bridge this yawning gap, otherwise the continent could be left behind for ever.

Africa should be using some of its international aid to guarantee long-term education in science and technology for new generations: only then can our research be self-sufficient and our science capacity advance.

Khalid D. Awadelkarim National Cancer Institute, University of Gezira, Wad Medani, Sudan.

awadelkarim@gmail.com 